Proc. Estonian Acad. Sci. Eng., 2004, 10, 3, 198-208

\title{
Theoretical development and computer simulation of a bioimpedance measurement system
}

\begin{abstract}
Toivo Paavle
Department of Electronics, Tallinn University of Technology, Ehitajate tee 5, 19086 Tallinn, Estonia, toivo@elin.ttu.ee

Received 6 April 2004

Abstract. In this paper, theoretical conceptions of a novel bioimpedance measurement system (MS) are discussed. The proposed MS couples the lock-in measurement principles and a method of undersampling in digital signal processing. The MS is a mixed-signal system incorporating an analogue phase-locked loop (PLL) as the source of reference signal, demodulators for amplitude and phase demodulation, and a digital signal processor. It is shown that using a single PLL, simultaneous demodulation of two signals with different frequencies is possible. The theoretical conceptions of lock-in measurement and efficiency of the whole MS have been verified by means of special computer simulators, structures of which are presented. The results of this work can be considered as a preliminary study for the practical design.
\end{abstract}

Key words: bioimpedance, biomodulation, lock-in measurement, phase-locked loop, undersampling, signal-domain model, phase-domain model.

\section{INTRODUCTION}

The bioimpedance (BI), i.e., the electrical impedance of living tissues, is a complex variable, real and imaginary components of which can change due to different physiological processes (e.g., heart beating, breathing, etc.) $\left.{ }^{1,2}\right]$. The measurement of the BI can be accomplished using a test (excitation) current, preferably sinusoidal, injected through the patient's organ to be examined. The magnitude and phase shift (with respect to the test signal) of the response signal is measured. The vector of BI can be easily calculated after that. Actually, the measurement is complicated due to the variation of the BI components. It causes the amplitude (AM) and phase (PM) modulation of the response signal. This biomodulation carries useful information about physiological state of the patient, 
and therefore the response signal must be demodulated to extract the embedded information.

Several methods and schematic solutions exist for demodulation and measurement of the biomodulated signals $\left[^{3-6}\right]$. A novel solution, which integrates the lock-in measurement and method of synchronous undersampling for accomplishing the demodulation, was first proposed in $\left[{ }^{3}\right]$. The preliminary project was outlined as a single-frequency device. Below we develop this idea and introduce the principles of simultaneous two-frequency measurement, which we define as a two-dimensional one, keeping in view the feeding of the test current into an organ through geometrically disposed electrodes.

The theoretical principles of the MS were verified by means of special computer simulators, structures of which will be presented in the last chapter.

\section{BASICS OF BIOIMPEDANCE}

We assume that the bioimpedance vector $\dot{Z}=|\dot{Z}| \exp (j \Phi)$ can be characterized by an equivalent electrical circuit, as shown in Fig. $1 \mathrm{a}\left[{ }^{1-3}\right]$. A resistor $R_{\text {ext }}$ represents resistance to the extracellular current $I_{\text {ext }}$ between the cells of the living tissue, while $R_{\text {int }}$ and $C_{\text {int }}$ are the components of intracellular impedance. The Laplace transform of this equivalent electrical impedance can be expressed as

$$
Z(s)=\frac{R_{\mathrm{ext}}\left(\tau_{1} s+1\right)}{\tau_{2} s+1},
$$

where $\tau_{1}=R_{\text {int }} C_{\text {int }}$ and $\tau_{2}=\left(R_{\text {ext }}+R_{\text {int }}\right) C_{\text {int }}$

The flow of the excitation current $I_{\mathrm{exc}}=I_{\mathrm{ext}}+I_{\mathrm{int}}$ through this complex impedance causes the response voltage $V_{\text {rsp }}(s)=I_{\text {exc }}(s) Z(s)$, the static phase shift and magnitude of which depend on the frequency $f_{\text {exc }}$ of the test signal. Usually, $R_{\text {ext }}$ and $R_{\text {int }}$ are equal to several hundreds of ohms, while the scale of $C_{\text {int }}$ extends from some $\mathrm{nF}$ to $20 \mathrm{nF}\left[^{2,5,7}\right]$. Analysis of Eq. (1) shows that the maximal phase shift, $\max \left(\Phi_{\mathrm{PM}}\right)$, caused by the BI occurs at the excitation frequency

(a)

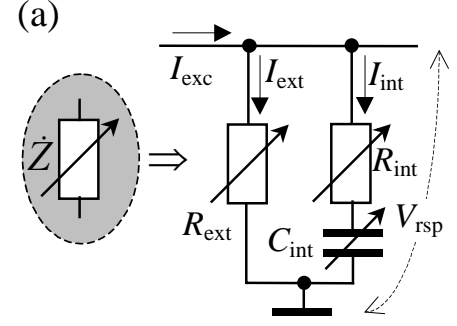

(b)

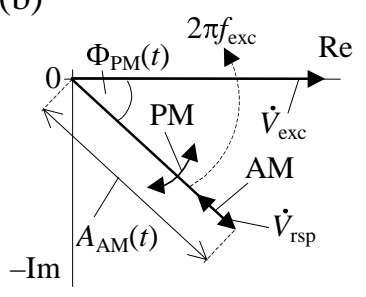

Fig. 1. Electrical equivalent of the bioimpedance (a); phasors of test and response signals (b). 


$$
f_{\mathrm{exc}}=\frac{1}{2 \pi C_{\mathrm{int}} \sqrt{R_{\mathrm{int}}\left(R_{\mathrm{ext}}+R_{\mathrm{int}}\right)}}=\frac{1}{2 \pi \sqrt{\tau_{1} \tau_{2}}}
$$

and in this case

$$
\max \left(\Phi_{\mathrm{PM}}\right)=\arctan \frac{\tau_{2}-\tau_{1}}{-2 \sqrt{\tau_{1} \tau_{2}}}=-\arctan \frac{R_{\mathrm{ext}}}{2 \sqrt{R_{\mathrm{int}}\left(R_{\mathrm{int}}+R_{\mathrm{ext}}\right)}} .
$$

For typical values of the BI components, $30^{\circ} \leq \max \left(\Phi_{\mathrm{PM}}\right) \leq 50^{\circ}$ at $20 \leq$ $f_{\text {exc }} \leq 50 \mathrm{kHz}\left[{ }^{8}\right]$. Dependence of the phase and relative amplitude on the BI components, being invariant with respect to $C_{\text {int }} f_{\text {exc }}$, are shown in Fig. 2, where $\left|\dot{Z}_{0}\right|$ denotes the magnitude of the vector $\dot{Z}$ at $f_{\text {exc }} \rightarrow 0$.

Considering that $R_{\text {ext }}=R_{\text {ext }}(t), R_{\text {int }}=R_{\text {int }}(t)$, and $C_{\text {int }}=C_{\text {int }}(t)$, the response signal at the sinusoidal excitation can be expressed as

$$
V_{\mathrm{rsp}}(t)=A_{\mathrm{AM}}(t) \sin \left(2 \pi f_{\mathrm{exc}} t+\Phi_{\mathrm{PM}}(t)\right)
$$

where $A_{\mathrm{AM}}(t)$ and $\Phi_{\mathrm{PM}}(t)$ are the modulated amplitude and phase, respectively. The corresponding phasor diagram is illustrated in Fig. 1b.

The task of the MS is to estimate the dynamics of the BI vector by demodulation of the response signal.

(a)
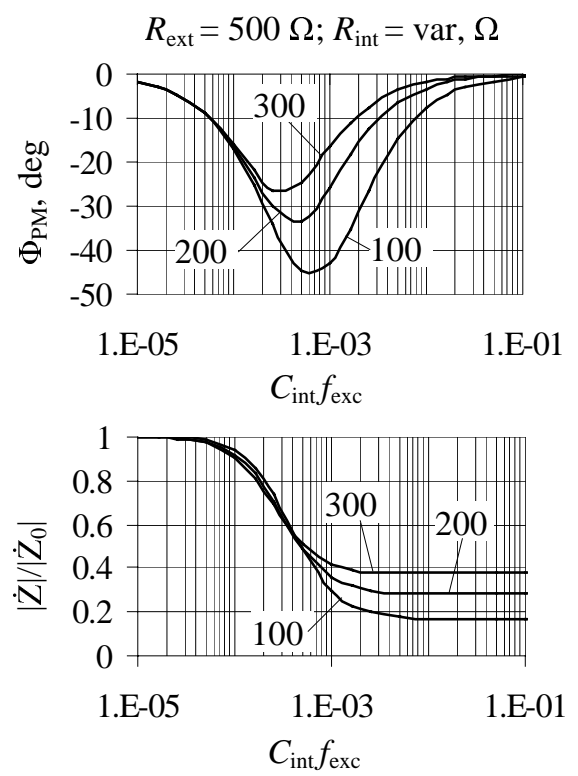

(b)
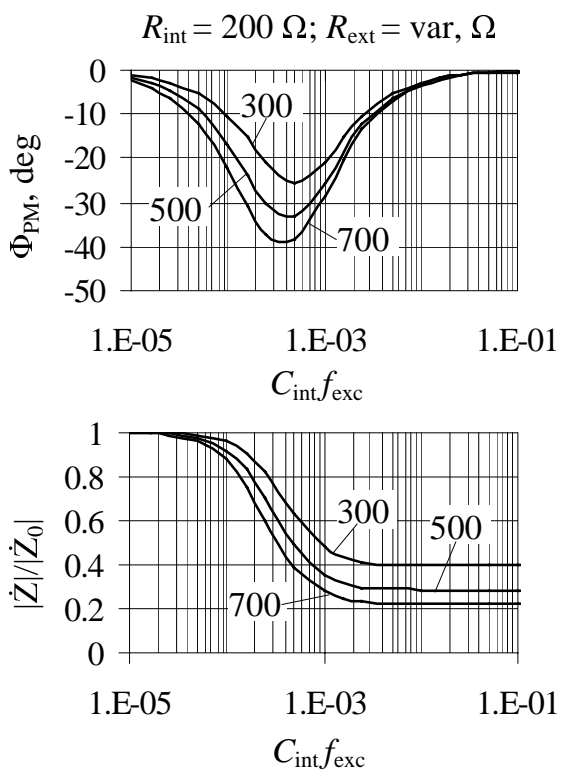

Fig. 2. Dependence of the phase and amplitude of response signal on the bioimpedance variations and excitation frequency: (a) at $R_{\text {ext }}=$ const; (b) at $R_{\text {int }}=$ const. 


\section{SINGLE-FREQUENCY (ONE-DIMENSIONAL) MEASUREMENT}

The main structure of the MS, proposed in $\left.{ }^{3,9}\right]$ is shown in Fig. 3. Its central module is the PLL frequency synthesizer (FS), producing reference signal $V_{\text {ref }}$ for the AM and PM demodulators. Processing the data of demodulation, generating excitation signal, and overall control are the tasks of the digital signal processor (DSP).

The free-running frequency $f_{\mathrm{fr}}$ of the voltage-controlled oscillator (VCO) must be selected at least equal to the maximal excitation frequency $\left(f_{\mathrm{fr}} \geq f_{\text {exc }}\right)$. The frequency of the VCO output is divided by the divider DIV $_{1}$ with division ratio $N_{1} \geq 1$ so that the frequency of $V_{\text {ref }}$ at the output of $\mathrm{DIV}_{1}$ is $f_{\text {ref }}=$ $f_{\text {vco }} / N_{1}=f_{\text {exc }}$. The error signal from the output of the multiplying phase detector (PD) is filtered by the low-pass filter (LPF). It suppresses the higher harmonics and its proper design has a great impact on the dynamics of the whole MS.

In fact, the low frequency of biomodulation (heart rhythm, $f_{\text {bio }}<<f_{\text {exc }}$ ) enables one to use the method of undersampling at AM demodulation. It means that we can ignore the Nyquist criterion in sampling the response signal and decrease the data amount at the DSP input substantially. Thus undersampling allows us to avoid unnecessary calculations and to implement a less powerful DSP.

The corresponding structure of the AM demodulator (synchronous sampler) incorporates an extra frequency divider $\mathrm{DIV}_{2}$ with division ratio $N_{2}$, and an analogue-to-digital converter (A/D). The reference frequency $f_{\text {ref }}$ is divided by the factor $N_{2}$ and the sampling rate $f_{\mathrm{s}}$ (undersampling) becomes equal to $f_{\mathrm{s}}=1 / f_{\text {ref }} / N_{2}=f_{\text {vco }} / N_{1} / N_{2}$. The trivial case of AM demodulation is explained in Fig. 4a. The instantaneous values of $V_{\text {rsp }}$ are measured and quantified at instances $t_{m}(m=1,2, \ldots)$ of certain zero-crossings of $V_{\text {ref }}$, which follow in accordance with the sampling rate (i.e., $t_{m+1}-t_{m}=1 / f_{\mathrm{s}}$ ). It results from the main properties of the PLL that its input signals $V_{\text {ref }}$ and $V_{\text {rsp }}$ must be in quadrature

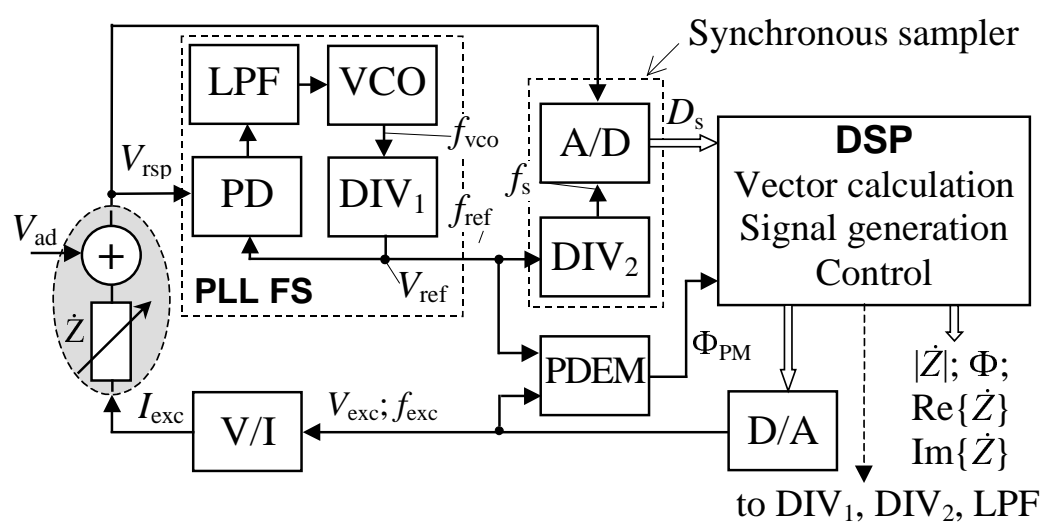

Fig. 3. Main structure of the measurement system. 
(shifted by $90^{\circ}$ ) in the locked state. Thus the sampling pulses $V_{\mathrm{s}}$, formed at instants $t_{m}$, coincide with the peak values of the response signal $\left(V_{\mathrm{s}}\left(t_{m}\right)=\right.$ $\left.A_{\mathrm{AM}}\left(t_{m}\right)\right)$, and the digitized data $D_{\mathrm{s}}$ from the A/D output permit to restore the response vector, taking into account the AM modulation.

For the PM demodulation, an analogue or digital solution is acceptable. In the first case, a multiplying PD can be used for continuos tracking of the phase difference $\Phi_{\mathrm{PM}}$ between the signal inputs $V_{\text {exc }}$ and $V_{\text {ref }}$. The product will be averaged by a LPF, while the output voltage $V_{\text {av }}$ of it determines the phase difference as

$$
\Phi_{\mathrm{PM}}=\arcsin \left(\pi V_{\mathrm{av}} / 2\right) .
$$

Let us remember that at rectangular $V_{\text {ref }}$ and sinusoidal $V_{\text {exc }}$ with unit magnitudes, $\max \left(V_{\mathrm{av}}\right)=2 / \pi$.

Another way for PM demodulation is direct measurement of the time difference $t_{x}=t_{m}^{\prime}-t_{m}$ between each $t_{m}$ and the following zero-crossing of $V_{\text {exc }}$ at $t_{m}^{\prime}$ (see respective phase angle $\psi$ in Fig. $4 \mathrm{a}$ ). In this case $\Phi_{\mathrm{PM}}=$ $\pi\left(1-4 t_{x} f_{\text {exc }}\right)=\pi / 2-\psi$.

Usually, the response signal $V_{\text {rsp }}$ includes some additive quasi-direct component $V_{\text {ad }}$, e.g., ECG signal, which must be extracted for adequate measurement of the BI. For that, generation of an additional sample at $t_{m}+T_{\text {ref }} / 2$ is necessary $\left(T_{\text {ref }}=1 / f_{\text {ref }}\right.$, Fig. $\left.4 \mathrm{~b}\right)$. Now, if the magnitudes of successive samples are $V_{1}=V_{\text {rsp }}\left(t_{m}\right)$ and $V_{2}=V_{\text {rsp }}\left(t_{m}+T_{\text {ref }} / 2\right)$, then $V_{\text {ad }}=$

(a)

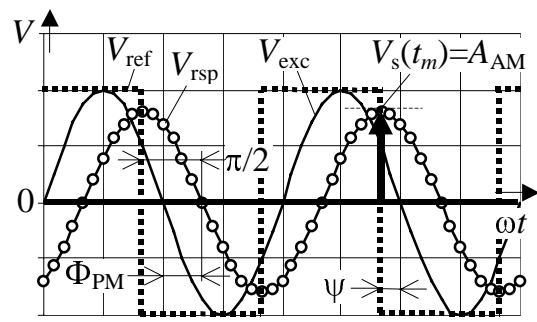

(c)

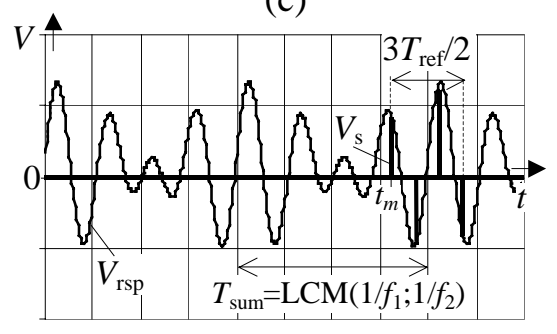

(b)

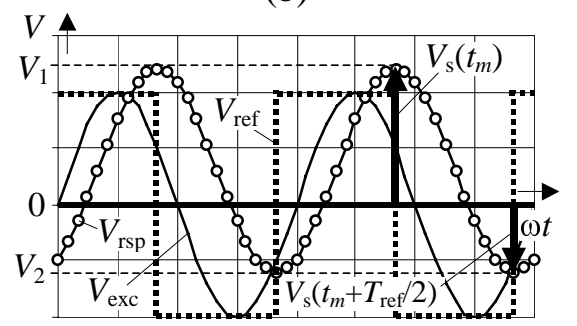

(d)

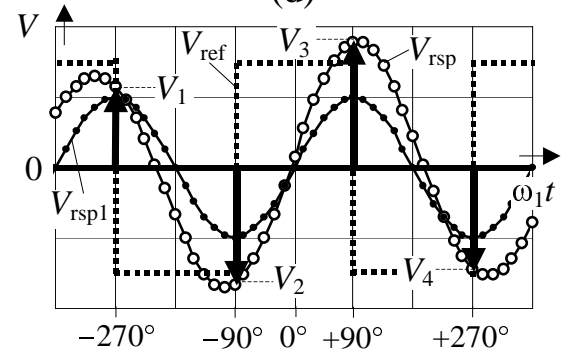

Fig. 4. Forming of synchronous samples: (a) - trivial case at single-frequency measurement; (b) - measurement in the case of an additive disturbance; (c)-example of the response signal at 2-dimensional measurement $\left(f_{2}=0.75 f_{1}\right)$; (d) - forming samples by 2-dimensional measurement. 
$\left(V_{1}+V_{2}\right) / 2$, while the magnitude of biomodulated response vector is $V_{\text {rsp }}=V_{1}-V_{\text {ad }}$.

\section{TWO-DIMENSIONAL MEASUREMENT}

Often, to get more information about the state of the patient's organs, the measurement is carried out at several frequencies. The simplest way is sequential exploiting of the signals with different frequencies. A more complicated case is simultaneous implementation and demodulation of two or more test signals, which are fed into the living tissue through spatially shifted electrodes (two- or multi-dimensional measurement, respectively). Next, let us analyse the opportunity to demodulate the sum of two test signals using a single PLL.

Let the two sinusoidal test signals $V_{\text {exc1 }}$ and $V_{\text {exc2 }}$ with unit amplitudes have frequencies $\omega_{1}=2 \pi f_{1}$ and $\omega_{2}=k \omega_{1}=2 \pi f_{2}$, respectively $(k<1$, while $N_{1} f_{1}(1-k)=N_{1}\left(f_{1}-f_{2}\right)$ must exceed the lock-in range of the VCO to avoid false locking to the $N_{1} f_{2}$ instead of required locking to $\left.f_{\mathrm{vco}}=N_{1} f_{1}\right)$. Now, considering the concurrent additive component $V_{\mathrm{ad}}$, the total response signal can be expressed as

$$
\begin{aligned}
V_{\mathrm{rsp}}(t) & =V_{\mathrm{rsp} 1}(t)+V_{\mathrm{rsp} 2}(t)+V_{\mathrm{ad}}(t) \\
& =A_{1}(t) \sin \left(\omega_{1} t+\theta_{1}(t)\right)+A_{2}(t) \sin \left(k \omega_{1} t+\theta_{2}(t)\right)+V_{\mathrm{ad}}(t) .
\end{aligned}
$$

As the PLL is tuned to the signal with the higher frequency $f_{1}$ (basic signal), then $f_{\text {ref }}=f_{1}$ in the locked state. The summarized response signal has the period $T_{\text {sum }}$, which is the lowest common multiple of the periods $T_{1}=1 / f_{1}$ and $T_{2}=1 / f_{2}$ of the signals (Fig. $4 \mathrm{c}$ ). This period determines the legal values of the sampling rate. For synchronized sampling of the summarized signal the sampling rate must be $f_{\mathrm{s}}=1 / M T_{\text {sum }}$, where $M=1,2,3, \ldots$ (on the other hand, the relation $f_{\mathrm{s}} \geq 10 f_{\text {bio }}$ should be followed for adequate demodulation).

Alike in the case of single-frequency measurement, the PM shift $\theta_{1}$ of the basic signal is measured via a particular phase demodulator PDEM $\left(\theta_{1}=\Phi_{\mathrm{PM}}\right.$, Fig. 3). To estimate the other unknown values we form the blocks of four sequential samples, which are generated at the instants $t_{m, n}(1 \leq n \leq 4)$ of successive zero-crossings of $V_{\text {ref }}\left(t_{m, n+1}-t_{m, n}=T_{\text {ref }} / 2\right)$ inside an interval of $\pm 3 \pi / 2$ of the $\omega_{1} t$ scale according to the sampling rate $\left(t_{m+1, n}-t_{m, n}=1 / f_{\mathrm{s}}\right)$. Assumption that $f_{\text {bio }}<<f_{2}<f_{1}=f_{\text {ref }}$ allows us to consider that the parameters to be measured are constant during the time $1.5 T_{\text {ref }}$ of the formation of the samples for the cycle $m$ of measurement. Unlike the one-dimensional measurement, the magnitudes $V_{n}$ of the respective samples are not equal to the peak values of $V_{\text {rsp }}$, but to the unknown instantaneous values $V_{\text {rsp }}\left(t_{m, n}\right)$ (Fig. 4d).

Assuming a locked system and defining $\alpha=\omega_{1} t$ and $\beta=\omega_{2} t=k \omega_{1} t$, we can describe every $m$-th block of samples by the system of equations as 


$$
V_{n}=A_{1} \sin \left(\alpha_{n}+\theta_{1}\right)+A_{2} \sin \left(\beta_{n}+\theta_{2}\right)+V_{\text {ad }}, \quad \text { for } n=1-4,
$$

where $V_{n}=V_{\text {rsp }}\left(t_{m, n}\right)$.

Due to the quadrature of $V_{\text {ref }}$ and $V_{\text {rspl }}$, the instants $t_{m, n}$ at every $m$ correspond to the phase angles $\alpha_{n}+\theta_{1}=\left\{-270^{\circ} ;-90^{\circ} ; 90^{\circ} ; 270^{\circ}\right\}$ of the $\omega_{1} t$ scale, which leads to $A_{1} \sin \left(\alpha_{n}+\theta_{1}\right)=(-1)^{n+1} A_{1}$. The current angles of the other signal can be expressed as $\beta_{n}=k \alpha_{n}$. For brevity, let us denote $s_{n}=\sin \beta_{n}$ and $c_{n}=\cos \beta_{n}$. We can rewrite (7) as

$$
V_{n}=(-1)^{n+1} A_{1}+A_{2}\left(s_{n} \cos \theta_{2}^{*}+c_{n} \sin \theta_{2}^{*}\right)+V_{\text {ad }},
$$

where

$$
\theta_{2}^{*}=\theta_{2}-k \theta_{1} \text {. }
$$

Symmetry of the angles $\alpha_{n}+\theta_{1}$ in respect to the origin means that $s_{1}=-s_{4}$, $s_{2}=-s_{3}, c_{1}=c_{4}$ and $c_{2}=c_{3}$. It simplifies solving of the system of equations. Deriving $V_{\text {ad }}$ from the system of equations (8) leads to

$$
V_{\mathrm{ad}}=\frac{c_{1}\left(V_{2}+V_{3}\right)-c_{2}\left(V_{1}+V_{4}\right)}{2\left(c_{1}-c_{2}\right)} .
$$

Next, denoting $V_{n}^{\prime}=V_{n}-V_{\text {ad }}$, we obtain

$$
\begin{gathered}
\theta_{2}^{*}=\arctan \frac{\left(s_{1}+s_{2}\right)\left(V_{1}^{\prime}+V_{2}^{\prime}+V_{3}^{\prime}+V_{4}^{\prime}\right)}{\left(c_{1}+c_{2}\right)\left[\left(V_{1}^{\prime}+V_{2}^{\prime}\right)-\left(V_{3}^{\prime}+V_{4}^{\prime}\right)\right]}, \\
A_{2}=\frac{V_{1}^{\prime}+V_{2}^{\prime}}{\left(s_{1}+s_{2}\right) \cos \theta_{2}^{*}+\left(c_{1}+c_{2}\right) \sin \theta_{2}^{*}}, \\
A_{1}=V_{1}^{\prime}-A_{2}\left(s_{1} \cos \theta_{2}^{*}+c_{1} \sin \theta_{2}^{*}\right) .
\end{gathered}
$$

Finally, the actual shift $\theta_{2}$ between the signals $V_{\mathrm{rsp} 2}$ and $V_{\mathrm{exc} 2}$ can be calculated from Eq. (9).

Thus using Eqs. (9) to (13) makes it possible to restore two different bioimpedance vectors and extract the concurrent dc-component $V_{\text {ad }}$ of the response signal.

\section{MODELLING OF THE MEASUREMENT SYSTEM}

For analysis of the analogue part of the MS, special software simulators were developed, which are the extended versions of typical models of the PLL FS $\left[{ }^{10}\right]$. In Fig. 5, structure of the signal-domain model of the two-dimensional MS is shown. If necessary, the model can be easily rearranged for the one-dimensional measurement, taking $V_{\text {ref2 }}=0$. 


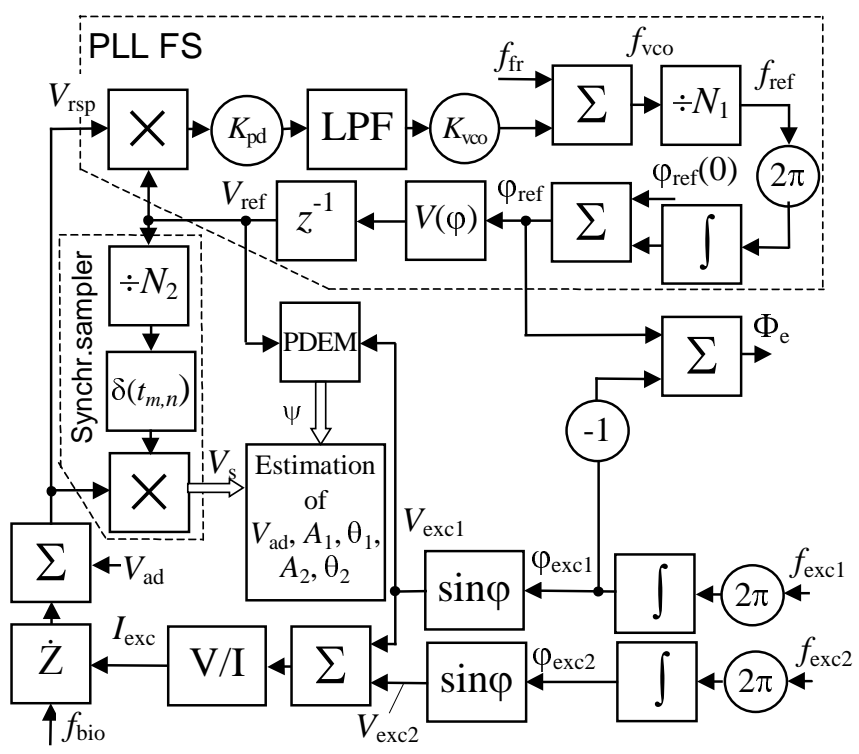

Fig. 5. Signal-domain model of the measurement system.

The basic integration relation $\varphi=\int \omega \mathrm{d} t$ was modelled using the method of running sum (Euler's backward method) by

$$
\varphi_{k}=\varphi_{k-1}+\omega_{k} \Delta t,
$$

where $\Delta t$ is the sampling interval of simulation, and $k=1,2, \ldots$

For calculating the output signal $y_{k}$ of the first order finite gain RC-circuit (lag filter), the iterative expression for non-ideal integration was used $\left[{ }^{10}\right]$ :

$$
y_{k}=y_{k-1}+\left(x_{k}-y_{k-1}\right)\left(1-\exp \left(-\Delta t / T_{\mathrm{p}}\right)\right),
$$

where $x_{k}$ is the input variable of the RC-circuit, and $T_{\mathrm{p}}=R C$ denotes the pole of respective transfer function. To assemble the model of a RC-circuit with one zero in the transfer function (lag-lead filter), the forward path with required gain was added to the model of integrator (14) or (15) $\left[{ }^{10}\right]$. Combining these principles, any necessary LPF structure and electrical equivalent of the BI can be modelled.

In Fig. 5, the factors $K_{\mathrm{pd}}$ and $K_{\mathrm{vco}}$ are the gains of PD and VCO, respectively. The dividers and voltage-to-current converter $V / I$ are modelled as simple gain elements, too. The block $z^{-1}$ marks the delay by a sampling interval $\Delta t$. The functional block $V(\varphi)$ forms the reference signal as $V_{\text {ref }}=$ $\operatorname{sgn}\left(\sin \varphi_{\text {ref }}\right)$. The synchronous sampler (AM demodulator), controlled by the divider $\div N_{2}$ (counts zero-crossings of $V_{\text {ref }}$ ) and counter of $n$ (if required), generates sampling pulses $V_{\mathrm{s}}=V_{\mathrm{rsp}} \delta\left(t-t_{m, n}\right)$, and performs multiplying of $V_{\mathrm{s}}$ and $V_{\text {rsp }}$. The products of multiplying together with the results from PM 


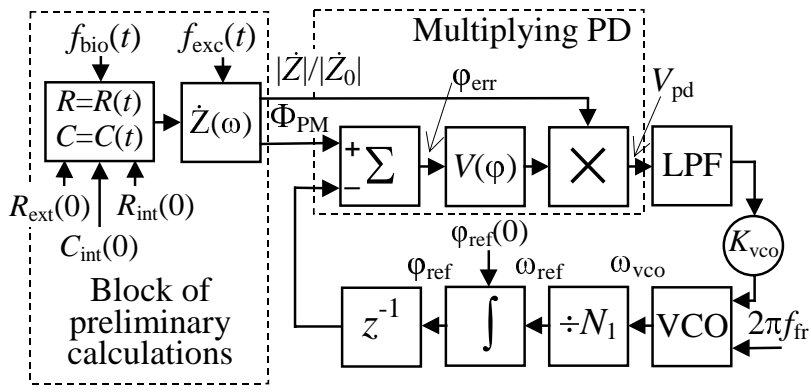

Fig. 6. Phase-domain model of the measurement system.

demodulator (PDEM, timing counter) are processed by the common trigonometric and algebraic routines. The running phase error $\Phi_{\mathrm{e}}$ is the special model variable, which cannot be directly measured in reality, but which is convenient for observing and analysing of the simulated transient processes.

For particular analysis of the dynamics of internal PLL, which has a primary importance over the whole MS, a special phase-domain simulator was designed. Though it does not enable to examine the waveforms of voltage signals, it is more suitable for study of the baseband transient processes due to its speed and simplicity. This type of models ignores the sampling nature of signals and operates with information, buried in the phase and frequency of the signals. The structure of the phase-domain model is shown in Fig. 6. The change of the input signal, caused by the biomodulation and variation of the excitation signal, is currently calculated by special input procedures. The error signal $\varphi_{\text {err }}$ of the feedback system (phase error) is directly evaluated as a difference between phase shift $\Phi_{\mathrm{PM}}$, caused by the PM modulation, and instantaneous phase $\varphi_{\text {ref }}$ of the reference signal. Assuming sinusoidal excitation and rectangular reference signal, the normalized characteristic of the PD expresses as $V(\varphi)=2 \sin \left(\varphi_{\text {err }}\right) / \pi$. The effect of AM is considered in the variable gain of the multiplying PD, proportional to the relative change of the amplitude due to the AM modulation.

\section{CONCLUSIONS}

The introduced mixed-signal measurement system permits to demodulate biomodulated signal from the living tissues and to estimate the variation of the bioimpedance vector. The earlier published basic description of the MS is updated for the measurement of the summarized response signal from the spatially disposed electrodes and for extracting the dc-component. The theoretical conceptions are verified by the computer simulation, for which two classes of special software simulators were developed. The particular tasks, which can be solved by means of these simulators, are mainly connected to the 
problems of non-linear system dynamics, especially to time-domain optimization and tracking of the test signal with changing excitation frequency.

The simulation results convince us that the high-quality bioimpedance measurement system, which integrates the principles of lock-in measurement and undersampling, can be accomplished successfully.

\section{ACKNOWLEDGEMENT}

This work was supported by the Estonian Science Foundation (grants Nos. 5892 and 5902).

\section{REFERENCES}

1. Grimnes, S. and Martinsen, O. G. Bioimpedance and Bioelectricity Basics. Academic Press, San Diego, 2000.

2. McAdams, E. T. and Jossinet, J. Tissue impedance: a historical overview. Physiol. Meas., 1995, 16, A1-A13.

3. Min, M. Electrical bioimpedance measurement: means and methods for applying in cardiac monitoring and pacing. In Proc. 1st World Congress on Biomimetics and Artificial Muscles. Albuquerque, NM, 2002, 6 p.

4. Min, M., Parve, T., Kukk, V., and Kuhlberg, A. An implantable analyzer of bio-impedance dynamics: mixed signal approach. IEEE Trans. Instrum. Meas., 2002, 51, 674-678.

5. Nebuya, S., Brown, B. H., Smallwood, R. H., Milnes, P., Waterworth, A. R., and Noshiro, M. Measurement of high frequency electrical transfer impedances from biological tissues. Electron. Lett., 1999, 35, 1985-1987.

6. Dudykevych, T., Gersing, E., Thiel, F., and Hellige, G. Impedance analyser module for EIT and spectroscopy using undersampling. Physiol. Meas., 2001, 22, 19-24.

7. Gordon, R. and Parve, T. Electrical bioimpedance measurement: methods and equivalent circuits. In Proc. 8th Biennial Baltic Electronics Conference (BEC2002). Tallinn, 2002, 363-366.

8. Osypka, M. and Gersing, E. Tissue impedance spectra and appropriate frequencies for EIT. Physiol. Meas., 1995, 16, A49-A55.

9. Min, M. and Paavle, T. A method of synchronous undersampling for complex bioimpedance measurement system. In Proc. European Conference on Circuit Theory and Design (ECCTD'03). Krakow, 2003, vol. 1, 302-305.

10. Paavle, T. System Level Modeling of Phase Locked Loops: Behavioral Analysis and Parameterization. PhD Thesis, Tallinn Technical University, Tallinn, 2003.

\section{Bioimpedantsi mõõtesüsteemi teoreetiline arendus ja arvutisimuleerimine}

\section{Toivo Paavle}

Artiklis tutvustatakse ja analüüsitakse uudset bioimpedantsi mõõtesüsteemi, mis kasutab testsignaali sünkroonset demoduleerimist ning demoduleerimis- 
resultaatide digitaalset töötlust bioimpedantsi määramiseks. Mõõtesüsteemi sünkroonsus tagatakse faasilukksüsteemil põhineva sagedussüntesaatori abil, mis on häälestatud testsignaali sagedusele. Kuivõrd biomodulatsiooni sagedus (südame rütm) on testsignaali sagedusest tunduvalt madalam, siis töödeldavate andmete hulga oluliseks vähendamiseks kasutatakse signaalide võimendamist tunduvalt alla Nyquisti kriteeriumi, jättes diskreetimissageduse bioimpedantsi adekvaatseks mõõtmiseks siiski piisavalt kõrgeks. Näidatakse võimalust aditiivse komponendi ekstraheerimiseks mõõdetavast signaalist. Detailselt vaadeldakse kahe erineva sagedusega testsignaali üheaegset demoduleerimist üheainsa faasilukksüsteemi baasil, kusjuures eeldatakse signaalide sisestust elusorganisse ruumiliselt nihutatud elektroodide kaudu (kahedimensiooniline mõõtmine). Lisaks mõõtesüsteemi teoreetilisele kirjeldusele selgitatakse süsteemi dünaamika uurimiseks koostatud arvutisimulaatorite tööd. Artiklit tuleks käsitada kui vastava mõõtesüsteemi projekteerimise ettevalmistavat etappi. 